\section{(6) OPEN ACCESS}

\title{
Biomechanical risk factors for carpal tunnel syndrome: a pooled study of 2474 workers
}

\author{
Carisa Harris-Adamson, ${ }^{1,2}$ Ellen A Eisen, ${ }^{1}$ Jay Kapellusch, ${ }^{3}$ Arun Garg, ${ }^{3}$ Kurt \\ T Hegmann, ${ }^{4}$ Matthew S Thiese, ${ }^{4}$ Ann Marie Dale, ${ }^{5}$ Bradley Evanoff, ${ }^{5}$ Susan Burt, ${ }^{6}$ \\ Stephen Bao, ${ }^{7}$ Barbara Silverstein, ${ }^{7}$ Linda Merlino, ${ }^{8}$ Fred Gerr, ${ }^{8}$ David Rempel ${ }^{9,10^{\prime}}$
}

\begin{abstract}
- Additional material is published online only. To view please visit the journal online (http://dx.doi.org/10.1136/ oemed-2014-102378).

For numbered affiliations see end of article.
\end{abstract}

\section{Correspondence to}

Prof. David Rempel, 1301

South 46th Street Bldg 163

Richmond, CA 94804, USA;

david.rempel@ucsf.edu

Received 4 June 2014 Revised 3 September 2014

Accepted 27 September 2014 Published Online First

16 October 2014

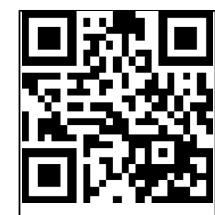

Open Access Scan to access mor free content

\section{(1) crossanta}

To cite: Harris-Adamson $C$, Eisen EA, Kapellusch J, et al. Occup Environ Med

2015;72:33-41.

\section{ABSTRACT}

Background Between 2001 and 2010, five research groups conducted coordinated prospective studies of carpal tunnel syndrome (CTS) incidence among US workers from various industries and collected detailed subject-level exposure information with follow-up of symptoms, electrophysiological measures and job changes.

Objective This analysis examined the associations between workplace biomechanical factors and incidence of dominant-hand CTS, adjusting for personal risk factors.

Methods 2474 participants, without CTS or possible polyneuropathy at enrolment, were followed up to 6.5 years (5102 person-years). Individual workplace exposure measures of the dominant hand were collected for each task and included force, repetition, duty cycle and posture. Task exposures were combined across the workweek using time-weighted averaging to estimate job-level exposures. CTS case-criteria were based on symptoms and results of electrophysiological testing. HRs were estimated using Cox proportional hazard models.

Results After adjustment for covariates, analyst ( $H R=2.17 ; 95 \% \mathrm{Cl} 1.38$ to 3.43$)$ and worker $(H R=2.08$; $95 \% \mathrm{Cl} 1.31$ to 3.39$)$ estimated peak hand force, forceful repetition rate (HR=1.84; $95 \% \mathrm{Cl} 1.19$ to 2.86 ) and per cent time spent (eg, duty cycle) in forceful hand exertions ( $\mathrm{HR}=2.05 ; 95 \% \mathrm{Cl} 1.34$ to 3.15 ) were associated with increased risk of incident CTS. Associations were not observed between total hand repetition rate, per cent duration of all hand exertions, or wrist posture and incident CTS.

Conclusions In this prospective multicentre study of production and service workers, measures of exposure to forceful hand exertion were associated with incident CTS after controlling for important covariates. These findings may influence the design of workplace safety programmes for preventing work-related CTS.

\section{INTRODUCTION}

Carpal tunnel syndrome (CTS) is a common peripheral entrapment neuropathy resulting from compression of the median nerve at the wrist that often results in high medical treatment costs, lost work time and associated disability. ${ }^{1}$ Although prior studies have related CTS to personal as well as workplace biomechanical factors such as hand force, repetition, awkward posture and vibration, ${ }^{2-6}$ exposure-response relationships are not well

\section{What this paper adds}

- Few large prospective studies using rigorous case-criteria, individual-level exposure data and appropriate control for confounding have examined associations between occupational biomechanical risk factors and carpal tunnel syndrome (CTS) incidence.

- Biomechanical risk factors associated with increased risk of developing CTS include time-weighted average peak hand force, forceful hand exertion repetition rate and the per cent time of forceful hand exertion.

- In this cohort, total repetition rate, per cent time of any hand exertion and wrist posture measures were not significantly associated with an increased risk for developing CTS.

described. Additionally, these studies were methodologically limited by cross-sectional design, non-specific CTS case-criteria (eg, symptoms only), self-reported or group-level exposure assessment, or limited sample size. Thus, for some prior studies, the observed risk factors may have been associated with true CTS, symptoms 'consistent with' CTS (but not necessarily including mononeuropathy), or other distal upper extremity musculoskeletal disorders (MSDs).

Prior studies also used different methods to assess workplace biomechanical exposures. For each exposure domain (force, repetition, posture), multiple assessment tools are available to quantify exposure at the task level. ${ }^{7}$ For example, hand-activity level (HAL) ratings, repetition rate, or the duration of exertion (eg, duty cycle) have all been used as metrics of hand activity. Furthermore, for jobs involving multiple tasks, there are several ways to summarise exposure at the job level. For example, job-level hand force can be estimated from multiple tasks by using peak force, average force, time-weighted average (TWA) force, or typical (most common) force. ${ }^{7}$ Currently there is little guidance regarding which of these techniques best predicts risk, nor consensus on which technique to use.

The importance of interaction between force and repetition on MSDs has been documented at the tissue level $^{8} 9$ and in epidemiological studies of working populations. ${ }^{4}{ }^{10}$ However, when tasks 
include multiple exposure domains, there is little consensus on methods for estimating the combined risk. Most studies measure each domain separately. ${ }^{11}$ Although some exposure assessment methods, such as the threshold limit value (TLV) for HAL, ${ }^{12}$ which estimate a single index for biomechanical hazard from multiple physical exposure domains may implicitly consider interaction, few studies have examined associations between CTS and exposures estimated with such multidomain methods. ${ }^{3} 13-15$ Therefore, methods of estimating the combined effects of concurrent exposures across domains (eg, repetition rate of forceful exertions) have been limited and are recognised as a barrier to furthering our understanding of risk factors for occupational MSDs. ${ }^{1116}$

To address these gaps, six research groups designed coordinated, multiyear, prospective epidemiological studies of US production and service workers from a variety of industries and used rigorous case-criteria and individual-level exposure assessments. After completion of data collection, subject-level demographic and longitudinal data including symptom assessments, physical examination findings, electrophysiological measures and workplace biomechanical factors were pooled. ${ }^{11}{ }^{17}$ Previously, we described the relationships between personal factors, occupational psychosocial factors and duration of employment with CTS incidence. ${ }^{18}$ This analysis pooled data from five of the six study sites to examine associations between biomechanical exposures and incident CTS while adjusting for personal factors.

\section{METHODS}

\section{Study participants and procedures}

\section{Participants}

The pooled study cohort consisted of data from five research groups. Participants in all studies were at least 18 years of age, employed at a company where some workers performed hand-intensive activities. Details on the study designs and methods of pooling exposure ${ }^{11}$ and health outcome ${ }^{17}$ data are provided elsewhere (site F, a sixth site, was not eligible for pooling because subject-level exposure data were not collected). A total of 3214 workers were eligible for participation. Participants were excluded from analysis if they met the case criteria for CTS or possible polyneuropathy at enrolment (ie, baseline). Most of the participants worked in the manufacturing $(83 \%)$, service $(9 \%)$ or agriculture $(6 \%)$ sectors.

\section{Data collection}

In all five studies, questionnaires were administered to participants at enrolment to collect information on work history, demographics, medical history and musculoskeletal symptoms. Electrodiagnostic studies (EDS) of median and ulnar nerve function across the wrist were administered to all participants and are described elsewhere. ${ }^{17}$ Depending on the study group, EDS was either administered to all participants at regular intervals regardless of symptom status or only to those reporting upper limb symptoms. ${ }^{17}$ Follow-up assessments of symptoms and EDS were performed at different intervals across the five studies. ${ }^{11} 17$ Investigators responsible for collecting health outcome data were blinded to participant exposure status.

\section{Biomechanical exposure}

Ten measures of workplace biomechanical exposures were collected at the task level for all participants: two measures of hand force, three measures of hand repetition, two measures of hand exertion duty cycle, two measures of wrist posture and one measure of hand vibration. ${ }^{11}$ Exposure estimates were based on a trained analyst's observation of each participant performing his/her usual work tasks, measurement of hand forces applied to complete each task, videotape analysis of the task, and interviews of participants or their supervisors. These analysts were blinded to health outcome.

Specifically, the pooled data set included estimates of the highest hand force requirements for a task as estimated by the worker (worker-rated peak hand force) and the analyst (analyst-rated peak hand force) using the Borg CR-10 rating scale. ${ }^{19}$ The repetitiveness of tasks was estimated by the analyst using the HAL scale. The HAL scale is one variable used in the HAL for TLV; the HAL for TLV is an index that combines repetition and peak hand force. The association of HAL for TLV with CTS will be evaluated in a separate publication. Other temporal exertion patterns for repetition, duty cycle and posture were determined by detailed time studies of task-level videos. ${ }^{11}$ These included the number of all exertions per minute (total hand repetition rate) and the number of forceful exertions per minute (forceful hand repetition rate). Forceful exertions were those requiring $\geq 9 \mathrm{~N}$ pinch force or $\geq 45 \mathrm{~N}$ of power grip force or a Borg CR- $10 \geq 2$. Estimates of force were based on measurement of the force required for the task, the weights of parts or tools, or force matching. Duty cycle was quantified for all hand exertions (\% time all exertions) and forceful hand exertions (\% time forceful exertions). Posture was quantified as the $\%$ time in $\geq 30^{\circ}$ wrist extension (\% time $\geq 30^{\circ}$ wrist extension) and the $\%$ time in $\geq 30^{\circ}$ wrist flexion (\% time $\geq 30^{\circ}$ wrist flexion). Finally, exposure to hand vibration (yes/no) observed by the analyst during a task was recorded.

Exposures were measured at the individual task level at all study sites at the time of participant enrolment and measured again if the job changed, thus creating a time series of exposure information. Three standard approaches were applied to summarise the task-level exposures at the job level: peak (the highest exposure across all tasks), typical (the exposure of the most commonly performed task) and TWA (a proportional weighting of each task's exposure value by the proportion of time the task was performed across the week). Peak, typical and TWA exposures were highly correlated across participants $(r=0.84-0.99)$; therefore, only TWA measures (which included information from all tasks performed) were used for this analysis.

\section{Outcome}

The study outcome was incident CTS of the dominant hand and required (1) symptoms of tingling, numbness, burning or pain in the thumb, index finger or long finger and (2) EDS results demonstrating median mononeuropathy at the wrist. ${ }^{20}$ Median mononeuropathy was defined as (1) peak median sensory latency $>3.7 \mathrm{~ms}$ or onset median sensory latency $>3.2 \mathrm{~ms}$ at $14 \mathrm{~cm}$, (2) motor latency $>4.5 \mathrm{~ms}$, (3) transcarpal sensory difference of $>0.85 \mathrm{~ms}$ (difference between median and ulnar nerve sensory latency across the wrist), or (4) an absent latency value consistent with an abnormal EDS and EDS evidence of normal ulnar nerve physiology (ulnar sensory peak latency $<3.68 \mathrm{~ms}$ ). Participants with symptoms consistent with CTS and concurrent abnormal median and ulnar nerve EDS were classified as possible polyneuropathy and were censored at the time that the possible polyneuropathy case definition criterion was met. ${ }^{18}$ All EDS latency values were temperature adjusted to $32^{\circ} \mathrm{C}$. Individuals who were symptomatic without a subsequent EDS were censored at the last date of known case status. Person-time was calculated as the number of days from enrolment to an abnormal EDS with symptoms or censoring due to possible polyneuropathy, dropout or study termination. 
Personal factors

All studies collected participant age, gender, body mass index (BMI), race/ethnicity, education, smoking status, hand dominance, and comorbid medical conditions such as rheumatoid arthritis, diabetes mellitus and thyroid disease. Prior carpal tunnel release and disorders of the distal upper extremity were also assessed. General health was assessed on a five-point scale. Total years worked at the current employer was self-reported at study enrolment.

\section{Statistical analysis}

HRs were estimated using Cox proportional hazards regression with robust CIs adjusted for potential confounding. For each exposure measure, the cohort was split into three equal size groups based on the exposure distribution. Potential confounding by personal factors was evaluated empirically. Specifically, covariates that were associated with each outcome $(\mathrm{p} \leq 0.20$ and had less than $10 \%$ missing data) were initially included in each model and then removed sequentially, in descending order of probability (with the covariate having the highest $\mathrm{p}$ value removed first). Covariates that, when removed from the model, resulted in a change of the effect estimate of the primary exposure variable by more than $10 \%$ were considered confounders and subsequently retained in the final multivariable model. To further minimise bias, models were also adjusted by study site and the exposure variable from each of the other domains (force, repetition, duty cycle and posture) with the least amount of missing data. As previous distal upper extremity disorders are (1) expected to be associated with the same exposures as CTS and (2) are not believed to be an independent risk factor for CTS, this variable was not considered a confounder for these analyses. ${ }^{21}$ The interactions of force and repetition were assessed by stratifying models using a median split of the exposure distribution at baseline. The healthy worker survivor effect was assessed by stratifying models on more or less than 3 years of work at enrolment, a threshold chosen to achieve an adequate sized referent group. To examine the impact of our definition of possible polyneuropathy, an additional post-hoc analysis was performed using concurrent abnormal median and ulnar nerve latencies regardless of median nerve symptoms as the definition for possible polyneuropathy. The functional form of the relationships between CTS and biomechanical exposures were assessed using penalised splines ${ }^{22}$ in a Cox model (R Core Team, Vienna, Austria). All other analyses were implemented with the Stata statistical package (Stata, College Station, Texas, USA).

\section{RESULTS}

Of the initial 3214 workers, 364 were excluded due to CTS $(\mathrm{N}=309)$ or possible polyneuropathy $(\mathrm{N}=55)$ at enrolment. Of the remaining 2850 eligible workers, 376 were dropped due to lack of exposure data or loss to follow-up for a participation rate of $86.8 \%$ (figure 1). There were 179 (7.2\%) incident CTS cases occurring over 5103 years of follow-up, for an incident rate of 3.51 per 100 person-years (table 1). The mean age at baseline was 40.8 years $(\mathrm{SD}=11.1)$ and $88 \%$ had no reported medical condition. The median years worked at the same company at baseline was 6.1 years (IQR 2.3-12) and most participants $(84 \%)$ worked the day shift. The median follow-up time was 2 years (IQR $=1-2.9$ ) with $10 \%$ of participants having less than 6 months of follow-up time and $10 \%$ having more than 4.7 years.

Correlations between most demographic and exposure variables were low $(\mathrm{r}=-0.01$ to 0.19$)$. However, as expected, working years and age were correlated $(r=0.48)$. Among the biomechanical variables, correlations greater than $\mathrm{r}=0.5$ were observed for forceful hand repetition rate and total hand repetition rate $(\mathrm{r}=0.54)$ and forceful hand repetition rate and $\%$ time in forceful hand exertion $(\mathrm{r}=0.76)$.

Baseline exposure results are presented in table 2. Differences between all (total) exertions and forceful exertions are best observed by inspection of the metrics used to depict repetition rate and duty cycle. Specifically, the median total hand repetition rate (18.0 exertions/min; IQR 10.1-31.6) was more than three times the forceful hand repetition rate (5.3 exertions/min; IQR 1.4-13.3). Similarly, the median \% time all hand exertions (67.2\% time; IQR 53.6-80.4) was more than three times the \% time forceful hand exertions (20.0\% time; IQR 6.3-37.9). Approximately $63 \%$ of participants were exposed to vibration during all of their tasks, $8 \%$ were exposed to vibration during some tasks and $29 \%$ were not exposed to vibration at all.

Crude and adjusted estimates of the associations between each biomechanical exposure and incident CTS are presented in table 3. When models were adjusted for age, gender, BMI, study site and exposure to other biomechanical domains, several statistically significant exposure-response relationships were observed.

Statistically significant monotonic increases in risk were observed for participants in the middle and upper tertiles of worker as well as analyst-rated peak hand force. Specifically, for the analyst-rated peak hand force, those in the middle tertile had a $60 \%$ increase in CTS risk $(\mathrm{HR}=1.59$; 95\% CI 1.09 to 2.34) and those in the highest tertile had a $117 \%$ increase in CTS risk $(\mathrm{HR}=2.17$; 95\% CI 1.38 to 3.43$)$ when compared with the reference group. Similar magnitude increases were observed for worker-rated peak hand force. The penalised cubic spline fit of the adjusted association also demonstrated a near linear association between analyst-rated peak force and incident CTS over peak hand force ratings of zero to seven (see online supplementary figure S1a). For values greater than seven the CI was wider and the precision of the estimate was lower due to relatively few workers having such high exposure.

The adjusted model for the analyst HAL scale demonstrated a statistically significant increased risk for the middle tertile $(\mathrm{HR}=1.54 ; 95 \%$ CI 1.02 to 2.32$)$ but not the upper tertile $(\mathrm{HR}=1.32 ; 95 \% \mathrm{CI} 0.87$ to 2.02$)$. For the two video analysis measures of hand repetition, an increased rate of CTS in the adjusted models was observed for forceful hand repetition rate

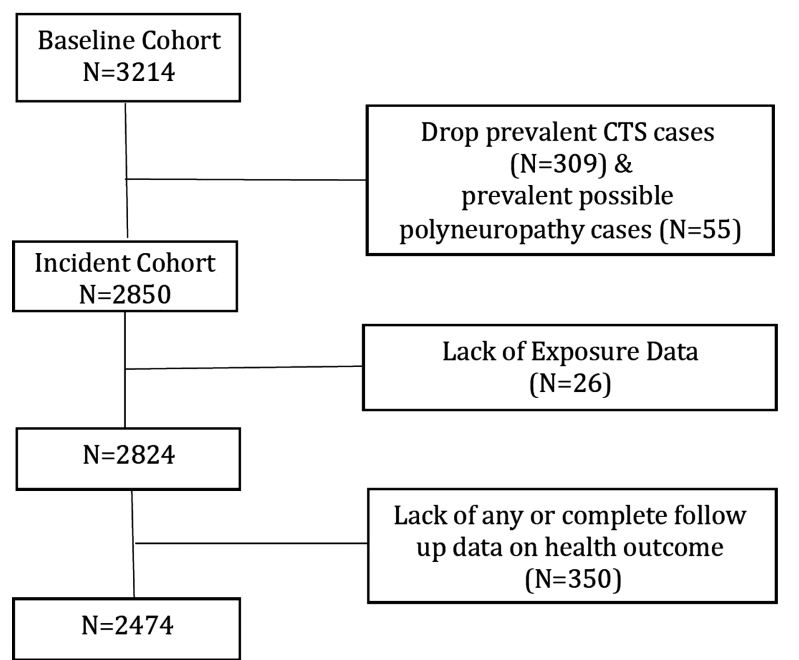

Figure 1 Cohort description (CTS, carpal tunnel syndrome) 
but not for total hand repetition rate. When compared with the lowest tertile of forceful hand repetition rate, the HRs for the middle tertile and upper tertile were 1.53 (95\% CI 1.05 to $2.25)$ and 1.84 (95\% CI 1.19 to 2.86), respectively.

Table 1 Demographics and related characteristics

\begin{tabular}{|c|c|c|c|}
\hline & $\begin{array}{l}\text { Total } \\
\mathrm{N}=2474\end{array}$ & $\mathbf{N}$ & $\begin{array}{l}\text { CTS } \\
\text { cases (n) }\end{array}$ \\
\hline Gender* & & 2474 & 179 \\
\hline Male & $1200(48 \%)$ & & 65 \\
\hline Female & $1274(52 \%)$ & & 114 \\
\hline Age (years) & & 2474 & 179 \\
\hline$<30$ years & $490(20 \%)$ & & 25 \\
\hline$\geq 30 \&<40$ years & $614(25 \%)$ & & 39 \\
\hline$\geq 40 \&<50$ years & $793(32 \%)$ & & 64 \\
\hline$\geq 50$ years & $577(23 \%)$ & & 51 \\
\hline Ethnicity $\dagger$ & & 2151 & 158 \\
\hline Caucasian & $1267(51 \%)$ & & 112 \\
\hline Hispanic & $509(21 \%)$ & & 16 \\
\hline African American & $164(7 \%)$ & & 14 \\
\hline Asian & $139(6 \%)$ & & 9 \\
\hline Other & $72(3 \%)$ & & 7 \\
\hline Education & & 2449 & 175 \\
\hline Some high school or less & $495(20 \%)$ & & 32 \\
\hline High school graduate or above & $1954(79 \%)$ & & 143 \\
\hline Handedness & & 2474 & 179 \\
\hline Left handed & $192(8 \%)$ & & 16 \\
\hline Right handed & $2282(92 \%)$ & & 163 \\
\hline Body mass index* & & 2462 & 178 \\
\hline Body mass index $(<25)$ & $804(33 \%)$ & & 35 \\
\hline $\begin{array}{l}\text { Body mass index ( } \geq 25 \&<30 \text { : } \\
\text { overweight) }\end{array}$ & $826(33 \%)$ & & 59 \\
\hline Body mass index ( $\geq 30$ : obese) & $832(34 \%)$ & & 84 \\
\hline General health $\dagger$ & & 2041 & 161 \\
\hline Very good or excellent & $884(36 \%)$ & & 55 \\
\hline Good & $881(36 \%)$ & & 83 \\
\hline Fair or poor & $276(11 \%)$ & & 23 \\
\hline Medical condition & & 2469 & 179 \\
\hline No medical condition & $2182(88 \%)$ & & 153 \\
\hline Current medical condition & $287(12 \%)$ & & $26 \ddagger$ \\
\hline Diabetes & $99(4 \%)$ & & 7 \\
\hline Rheumatoid arthritis & $54(2 \%)$ & & 5 \\
\hline Thyroid disease (hyper/hypo) & $131(5 \%)$ & & 15 \\
\hline Pregnancy & $19(1 \%)$ & & 0 \\
\hline Previous DUE disorder & & 1830 & 134 \\
\hline No previous DUE & $1578(64 \%)$ & & 105 \\
\hline Previous DUE & $252(10 \%)$ & & 29 \\
\hline Smoking status & & 2459 & 176 \\
\hline Never smoked & $1344(54 \%)$ & & 93 \\
\hline Currently smoke & $649(26 \%)$ & & 50 \\
\hline Previously smoked & $466(19 \%)$ & & 33 \\
\hline Years worked at enrolment & & 2455 & 176 \\
\hline$\leq 1$ year & $262(11 \%)$ & & 17 \\
\hline$>1 \& \leq 3$ years & $503(20 \%)$ & & 26 \\
\hline$>3 \& \leq 7$ years & $564(23 \%)$ & & 46 \\
\hline$>7 \& \leq 12$ years & $567(23 \%)$ & & 50 \\
\hline$>12$ years & $559(23 \%)$ & & 37 \\
\hline $\begin{array}{l}\text { Missing per cent for each characteris } \\
{ }^{*} p \leq 0.20 \text { and retained in models. } \\
t p \leq 0.20 \text { but excluded from models } \\
\neq 0 \text { ne participant had two medical c } \\
\text { CTS, carpal tunnel syndrome; DUE, }\end{array}$ & $\begin{array}{l}\text { nts missing datz } \\
\text { sing }>10 \% \text { datc } \\
\text { extremity. }\end{array}$ & & \\
\hline
\end{tabular}

Additionally, a penalised cubic spline fit demonstrated a near linear association up to 30 exertions/min, at which point the precision declined due to the low number of participants with exposures above this level (see online supplementary figure S1b).

A similar pattern was observed for the duty cycle measures of hand exertion. In the adjusted models, the per cent time that the fingers were exerting any level of force (\% time all hand exertions) was not associated with incident CTS (table 3). A post-hoc analysis of $\%$ time all hand exertions, using cutpoints of $30 \%$ duration $(\mathrm{HR}=0.85 ; 95 \% \mathrm{CI} 0.41$ to 1.76$)$ and $60 \%$ duration $(\mathrm{HR}=1.00 ; 95 \% \mathrm{CI} 0.50$ to 1.99$)$ also demonstrated no significant associations (data not shown). In contrast, CTS incidence was significantly and monotonically associated with per cent time performing a forceful grip or pinch (\% time forceful hand exertions). Specifically, those in the upper tertile of this measure had twice the rate of incident CTS compared with those in the lowest tertile $(\mathrm{HR}=2.05,95 \% \mathrm{CI} 1.34$ to 3.15). A model using a penalised cubic spline demonstrated a near linear increase in rate of CTS up to $50 \%$ time in forceful hand exertions beyond which the precision declined due to small sample size at the higher exposure level (see online supplementary figure S1c).

No associations were observed in the crude or adjusted models between measures of wrist posture or vibration and CTS incidence (table 3).

In a post-hoc analysis, the interaction of hand force and repetition rate on CTS risk was investigated by stratifying the analyst-rated peak hand force HRs by total hand repetition rate (table $4 \mathrm{~A}$ ) and total hand repetition rate by analyst-rated peak hand force (table 4B). For the first stratification, the cohort was split on median total hand repetition rate (18.1 repetitions / $\mathrm{min}$; table 4A). A stronger association between analyst-rated peak force and CTS was observed in the high repetition group compared with the lower repetition group. However, when total hand repetition rate was stratified by analyst-rated peak hand force (Borg CR-10 of 3), there was no association with incident CTS in either the low-force or high-force subgroups.

To explore the effect of years worked on the exposure-response relationships, analyses of associations between incident CTS and analyst-rated peak hand force, forceful hand repetition rate and \% time forceful hand exertions were

Table 2 Summary of baseline job-level time-weighted average exposures

\begin{tabular}{lccc}
\hline & (N) & Median (IQR) & Range \\
\hline $\begin{array}{l}\text { Force measures } \\
\quad \text { Peak hand force: worker rated }\end{array}$ & 2168 & $3(2.0-4.5)$ & $0-10$ \\
$\quad \begin{array}{l}\text { Peak hand force: analyst rated } \\
\text { Repetition measures }\end{array}$ & 2408 & $3(1.8-4)$ & $0-10$ \\
$\quad$ HAL scale: analyst & 2423 & $4.9(4-6)$ & $0-10$ \\
$\quad \begin{array}{l}\text { Total hand repetition rate } \\
\text { Forceful hand repetition rate }\end{array}$ & 2165 & $18.0(10.1-31.6)$ & $0.7-100$ \\
$\begin{array}{l}\text { Duty cycle } \\
\text { \% time all hand exertions }\end{array}$ & 2442 & $5.3(1.4-13.3)$ & $0-95.7$ \\
$\quad \%$ time forceful hand exertions & 2442 & $67.2(53.6-80.4)$ & $0.7-100$ \\
$\begin{array}{l}\text { Posture measures } \\
\text { \% time } \geq 30^{\circ} \text { wrist extension }\end{array}$ & 2433 & $5.6(0.3-37.9)$ & $0-100$ \\
$\quad \%$ time $\geq 30^{\circ}$ wrist flexion & 2432 & $0.6(0-3.5)$ & $0-62.5$ \\
\hline HAL, hand-activity level. & & &
\end{tabular}


Table 3 Crude and adjusted hazard rate ratios for carpal tunnel syndrome and individual time-weighted average biomechanical exposures

\begin{tabular}{|c|c|c|c|c|c|c|c|c|c|}
\hline & \multirow[b]{2}{*}{ Cutoffs } & \multicolumn{4}{|l|}{ Crude } & \multicolumn{4}{|l|}{ Adjusted } \\
\hline & & Cohort (N) & Cases (n) & HR & $95 \% \mathrm{Cl}$ & Cohort (N) & Cases (n) & HR & $95 \% \mathrm{Cl}$ \\
\hline \multicolumn{10}{|l|}{ Force measures } \\
\hline Peak hand force: worker rated* & & 2233 & 157 & & & 1955 & 142 & & \\
\hline Lower tertile & $\leq 2.1$ & & 38 & 1.00 & & & 33 & 1.00 & \\
\hline Middle tertile & $>2.1 \& \leq 4$ & & 62 & 1.22 & 0.81 to 1.84 & & 57 & 1.70 & 1.08 to 2.68 \\
\hline Upper tertile & $>4$ & & 57 & 1.62 & 1.07 to 2.44 & & 52 & 2.08 & 1.31 to 3.29 \\
\hline Peak hand force: analyst rated ${ }^{*}$ & & 2410 & 176 & & & 2038 & 153 & & \\
\hline Lower tertile & $\leq 2.5$ & & 58 & 1.00 & & & 49 & 1.00 & \\
\hline Middle tertile & $>2.5 \& \leq 4$ & & 75 & 1.16 & 0.82 to 1.64 & & 65 & 1.59 & 1.09 to 2.34 \\
\hline Upper tertile & $>4$ & & 43 & 1.65 & 1.11 to 2.46 & & 39 & 2.17 & 1.38 to 3.43 \\
\hline \multicolumn{10}{|l|}{ Repetition measures } \\
\hline HAL scale: analyst ratedt & & 2425 & 177 & & & 2299 & 164 & & \\
\hline Lower tertile & $\leq 4$ & & 66 & 1.00 & & & 59 & 1.00 & \\
\hline Middle tertile & $>4 \& \leq 5.3$ & & 50 & 1.36 & 0.94 to 1.95 & & 48 & 1.54 & 1.02 to 2.32 \\
\hline Upper tertile & $>5.3$ & & 61 & 1.21 & 0.85 to 1.73 & & 57 & 1.32 & 0.87 to 2.02 \\
\hline Total hand repetition rate: video analysis ${ }^{\dagger}$ & & 2107 & 159 & & & 2038 & 153 & & \\
\hline Lower tertile & $\leq 13$ & & 61 & 1.00 & & & 57 & 1.00 & \\
\hline Middle tertile & $>13 \& \leq 26$ & & 57 & 0.94 & 0.66 to 1.35 & & 56 & 1.12 & 0.76 to 1.65 \\
\hline Upper tertile & $>26$ & & 41 & 0.77 & 0.52 to 1.15 & & 40 & 0.94 & 0.59 to 1.5 \\
\hline Forceful hand repetition rate: video analysisł & & 2384 & 170 & & & 2354 & 166 & & \\
\hline Lower tertile & $\leq 2.6$ & & 60 & 1.00 & & & 59 & 1.00 & \\
\hline Middle tertile & $>2.6 \& \leq 9.6$ & & 60 & 1.16 & 0.81 to 1.66 & & 57 & 1.53 & 1.05 to 2.25 \\
\hline Upper tertile & $>9.6$ & & 50 & 1.26 & 0.87 to 1.84 & & 50 & 1.84 & 1.19 to 2.86 \\
\hline \multicolumn{10}{|l|}{ Duty cycle } \\
\hline$\%$ duration all hand exertions: video analysist & & 2107 & 159 & & & 2038 & 153 & & \\
\hline Lower tertile & $\leq 59 \%$ & & 45 & 1.00 & & & 42 & 1.00 & \\
\hline Middle tertile & $>59 \% \& \leq 76 \%$ & & 57 & 1.20 & 0.81 to 1.77 & & 56 & 1.12 & 0.75 to 1.67 \\
\hline Upper tertile & $>76 \%$ & & 57 & 1.29 & 0.87 to 1.91 & & 55 & 1.13 & 0.75 to 1.68 \\
\hline$\%$ duration forceful hand exertions: video analysisł & & 2384 & 170 & & & 2354 & 166 & & \\
\hline Lower tertile & $\leq 11 \%$ & & 57 & 1.00 & & & 56 & 1.00 & \\
\hline Middle tertile & $>11 \% \& \leq 32 \%$ & & 55 & 1.12 & 0.78 to 1.62 & & 53 & 1.46 & 0.98 to 2.17 \\
\hline Upper tertile & $>32 \%$ & & 58 & 1.48 & 1.03 to 2.13 & & 57 & 2.05 & 1.34 to 3.15 \\
\hline \multicolumn{10}{|l|}{ Posture measures } \\
\hline$\%$ time $\geq 30^{\circ}$ wrist extension: video analysis§ & & 2373 & 168 & & & 2038 & 153 & & \\
\hline Lower half & $\leq 5 \%$ & & 96 & 1.00 & & & 88 & 1.00 & \\
\hline Upper half & $>5 \%$ & & 72 & 0.90 & 0.66 to 1.23 & & 65 & 0.87 & 0.59 to 1.29 \\
\hline$\%$ time $\geq 30^{\circ}$ wrist flexion: video analysis§ & & 2374 & 168 & & & 2038 & 153 & & \\
\hline Lower half & $\leq 1 \%$ & & 86 & 1.00 & & & 83 & 1.00 & \\
\hline Upper half & $>1 \%$ & & 82 & 0.94 & 0.69 to 1.27 & & 70 & 0.83 & 0.60 to 1.15 \\
\hline \multicolumn{10}{|l|}{ Other } \\
\hline Vibration: analyst rated & & 2092 & 162 & & & 1719 & 139 & & \\
\hline Lower half & 0 & & 96 & 1.00 & & & 82 & 1.00 & \\
\hline Upper half & $>0$ & & 66 & 1.07 & 0.78 to 1.47 & & 57 & 1.04 & 0.69 to 1.55 \\
\hline $\begin{array}{l}\text { All models include age, gender, body mass index, study } \\
\text { *Adjusted for total repetition rate, } \% \text { duration all exertio } \\
\text { †Adjusted for peak force, } \% \text { time } \geq 30^{\circ} \text { wrist flexion. } \\
\text { ¥Adjusted for } \% \text { time } \geq 30^{\circ} \text { wrist flexion. } \\
\text { §Adjusted for peak force, total repetition rate, } \% \text { duratio } \\
\text { TAdjusted for peak force, total repetition rate, } \% \text { duratio } \\
\text { HAL, hand-activity level. }\end{array}$ & $\begin{array}{l}\% \text { time } \geq 30^{\circ} \mathrm{w} \\
\text { Il exertions. } \\
\text { Il exertions, \% ti }\end{array}$ & exion. & & & & & & & \\
\hline
\end{tabular}

conducted for the subgroup with less than 3 years of work at baseline and the subgroup with three or more years of work (table 4C-E). Somewhat higher HRs were observed for those who worked less than 3 years compared with those who had worked three or more years.

In a post-hoc analysis, when we changed the definition of possible polyneuropathy to be patients with concurrent abnormal median and ulnar nerve latencies regardless of symptoms $(\mathrm{N}=121)$, the adjusted HRs increased for the middle analyst-rated peak hand force tertile ( $\mathrm{HR}=1.82 ; 95 \% \mathrm{CI} 1.22$ to 2.71), the upper analyst-rated peak hand force tertile $(\mathrm{HR}=2.61 ; 95 \% \mathrm{CI} 1.62$ to 4.2$)$, forceful hand repetition rate $\left(\mathrm{HR}_{\text {middle tertile }}=1.74 ; 95 \% \mathrm{CI} 1.17\right.$ to $2.59 ; \mathrm{HR}_{\text {upper }}$ tertile $=2.1 ; 95 \%$ CI 1.32 to 3.32 ) and \% time forceful hand exertions ( $\mathrm{HR}$ middle tertile $=1.6 ; 95 \%$ CI 1.05 to 2.42 ; HR upper tertile $=2.39 ; 95 \%$ CI 1.54 to 3.71$)$. There was minimal change in the effect estimates of the other exposure variables. 
Table 4 Associations between selected workplace biomechanical exposures and incident carpal tunnel syndrome stratified by (A) repetition, (B) peak hand force, or (C-E) years worked at time of enrolment

\begin{tabular}{|c|c|c|c|c|}
\hline & Cohort (N) & Cases (n) & HR & $95 \% \mathrm{Cl}$ \\
\hline \multicolumn{5}{|l|}{ (A) Analyst-rated peak hand force stratified by total hand repetition rate } \\
\hline Analyst peak force: subgroup with $\leq 18.1$ repetitions/min & 1100 & 82 & & \\
\hline Lower tertile & & 35 & 1.00 & \\
\hline Middle tertile & & 27 & 1.03 & 0.60 to 1.77 \\
\hline Upper tertile & & 20 & 1.82 & 0.99 to 3.37 \\
\hline Analyst peak force: subgroup with $>18.1$ repetitions/min & 1033 & 71 & & \\
\hline Lower tertile & & 14 & 1.00 & \\
\hline Middle tertile & & 38 & 2.78 & 1.51 to 5.14 \\
\hline Upper tertile & & 19 & 2.97 & 1.41 to 6.27 \\
\hline \multicolumn{5}{|l|}{ (B) Total hand repetition rate stratified by analyst-rated peak hand force } \\
\hline Total repetition rate: subgroup with lower peak hand force $(\leq 3)$ & 1308 & 91 & & \\
\hline Lower tertile & & 36 & 1.00 & \\
\hline Middle tertile & & 29 & 1.01 & 0.59 to 1.73 \\
\hline Upper tertile & & 26 & 1.11 & 0.60 to 2.07 \\
\hline Total repetition rate: subgroup with higher peak hand force $(>3)$ & 878 & 62 & & \\
\hline Lower tertile & & 21 & 1.00 & \\
\hline Middle tertile & & 27 & 1.36 & 0.76 to 2.44 \\
\hline Upper tertile & & 14 & 0.64 & 0.30 to 1.37 \\
\hline \multicolumn{5}{|l|}{ (C) Analyst-rated peak hand force stratified by years worked at enrolment } \\
\hline Analyst peak hand force: subgroup with $<3$ years of work & 674 & 37 & & \\
\hline Lower tertile & & 10 & 1.00 & \\
\hline Middle tertile & & 16 & 1.83 & 0.80 to 4.17 \\
\hline Upper tertile & & 11 & 3.37 & 1.16 to 9.81 \\
\hline Analyst peak hand force: subgroup with $\geq 3$ years of work & 1345 & 113 & & \\
\hline Lower tertile & & 39 & 1.00 & \\
\hline Middle tertile & & 46 & 1.46 & 0.94 to 2.28 \\
\hline Upper tertile & & 28 & 1.88 & 1.12 to 3.18 \\
\hline \multicolumn{5}{|l|}{ (D) Forceful hand repetition rate stratified by years worked at enrolment } \\
\hline Forceful repetition rate: subgroup with $<3$ years of work & 727 & 40 & & \\
\hline Lower tertile & & 12 & 1.00 & \\
\hline Middle tertile & & 17 & 2.18 & 0.97 to 4.89 \\
\hline Upper tertile & & 11 & 2.78 & 0.93 to 8.27 \\
\hline Forceful repetition rate: subgroup with $\geq 3$ years of work & 1608 & 123 & & \\
\hline Lower tertile & & 45 & 1.00 & \\
\hline Middle tertile & & 39 & 1.45 & 0.93 to 2.28 \\
\hline Upper tertile & & 39 & 1.75 & 1.07 to 2.86 \\
\hline \multicolumn{5}{|c|}{ (E) \% duration forceful hand exertion stratified by years worked at enrolment } \\
\hline$\%$ duration forceful exertions: subgroup with $<3$ years of work & 727 & 40 & & \\
\hline Lower tertile & & 11 & 1.00 & \\
\hline Middle tertile & & 17 & 1.94 & 0.86 to 4.40 \\
\hline Upper tertile & & 12 & 2.53 & 0.90 to 7.09 \\
\hline$\%$ duration forceful exertions: subgroup with $\geq 3$ years of work & 1608 & 123 & & \\
\hline Lower tertile & & 44 & 1.00 & \\
\hline Middle tertile & & 34 & 1.32 & 0.83 to 2.12 \\
\hline Upper tertile & & 45 & 2.16 & 1.36 to 3.43 \\
\hline
\end{tabular}

\section{DISCUSSION}

In this prospective study of a working population, exposure-response relationships were observed between several measures of forceful hand exertion and incident CTS. The observed associations provide strong evidence for modifiable physical risk factors in the workplace. The strengths of the study were the large sample size, specific case-criteria and detailed exposure measures at the individual level. The wide range of industries, jobs and locations represented increases the heterogeneity of exposures and the generalisability of the findings. The incidence of CTS was 3.51 per 100-person-years, which was higher than the 0.17 rate reported from workers compensation data ${ }^{23}$ and lower than some studies of specific working populations (1.2-11.0 per 100-person-years). ${ }^{13} 1423$

Since there are several approaches to summarising exposure at the job level when workers perform more than one task, job-level exposure based on (1) peak, (2) typical and (3) TWA methods were calculated for each worker across all of his/her tasks. For this data set, regardless of the exposure domain (force, repetition, duty cycle, posture or vibration), the correlations between the three summary methods were high (range: $\mathrm{r}=0.84-0.99)$ because most jobs consisted of just one $(57 \%)$ 
task. Future studies using various summary methods among only participants who worked jobs with two or more tasks are needed in order to (1) compare the risk prediction performance among the exposure summary techniques, and (2) explore the implications of each technique on workplace injury prevention strategies.

The risk of CTS incidence increased monotonically across peak hand force categories, regardless of whether it was rated by the analyst or worker $(r=0.52)$. Approximately two-thirds of analyst and worker-rated peak hand force scores differed with $38 \%$ of scores rated higher by the worker (mean $=1.9 ; \mathrm{SD}=1.5$ ) versus $28 \%$ rated higher by the analyst (mean $=1.5 ; \mathrm{SD}=1.1$ ). Despite the differences between the two measures, both were associated with increased risk of CTS, thus validating the use of either scale for surveillance.

When hand repetition rate was considered independent of force (eg, total hand repetition rate), we observed no significant increase in rate of CTS. On the other hand, forceful hand repetition rate, a measure of simultaneous exposure to forceful and repetitive hand exertions, was significantly associated with an increased risk of CTS. The CTS incidence rate appeared to increase linearly with forceful hand repetition rate up to 30 repetitions/min (see online supplementary figure S1b), at which point the HR plateaued with widening CIs. Very few workers performed work that required more than 30 hand exertions/ minute at greater than a $45 \mathrm{~N}$ grip or $9 \mathrm{~N}$ pinch force, possibly due to the difficulty performing work at such exposure levels. Contrary to our results, several cross-sectional studies have reported associations between total hand repetition or wrist angular velocity and CTS. ${ }^{4} 10{ }^{24}$ One explanation may be that their repetition rates were, to some extent, a measure of forceful repetition rates (ie, the analyst may have only counted a hand motion as a repetition if it exceeded some minimum level of applied force). Alternatively, it could be that repetition is a risk factor for CTS only during low force tasks. However, this was not observed in the low force subgroup post-hoc stratified analysis of total hand repetition rate by analyst-rated peak hand force (table 4B).

The analyst-rated HAL scale captures hand repetition as well as recovery time ${ }^{12}$ and has been associated with distal upper extremity disorders and CTS in some prior studies ${ }^{13}{ }^{25}$ but not others. ${ }^{15}$ In our cohort, a $54 \%$ increase in rate of CTS occurred among participants with exposure in the middle tertile (eg, HAL scale $=4-5.3$ ) but the rate declined modestly in the upper tertile. These findings differ from a prospective study ${ }^{13}$ that reported a monotonic $37 \%$ increase in risk of CTS for every unit increase in HAL scale. Although the Bonfiglioli ${ }^{13}$ study and our study had similar sample sizes (2921 vs 2474), there were different CTS incidence rates (2.20 vs 3.51 per 100 -person-years), different jobs and different exposure levels. For example, the median value for HAL in the Bonfiglioli study ${ }^{13}$ was lower than in our study. In addition, the correlation between HAL and peak force was larger in the Bonfiglioli study (Spearman $r=0.42$ vs 0.18 ), suggesting that the minimum force threshold required for a 'hand exertion' was higher than in our study.

Similar to the findings for repetition, the per cent time performing any finger pinch or power grip (including light-force and high-force exertions) was not associated with CTS incidence regardless of whether exposure cut-points were based on the study population distribution or a priori selected values. However, the per cent time spent in forceful pinch or power grip increased the rate of CTS in a dose-response pattern. Participants with a per cent of time in forceful hand exertion between $11 \%$ and $32 \%$ (second tertile) had a $46 \%$ increase in the rate of CTS and those with per cent time in forceful hand exertion of more than $32 \%$ (third tertile) had twice the rate of CTS compared with the lowest tertile $(<11 \%)$. The decline in risk for CTS observed for those who spent more than $50 \%$ of their time in forceful exertion (see online supplementary figure S1c) could be a reflection of the scarcity of data above that exposure level. It could also indicate an attenuation commonly observed in other studies of associations between occupational exposures and adverse health effects and represent a healthy worker survivor bias resulting from the self-selection of the most affected workers out of jobs with the highest levels of exposure. ${ }^{26}$

Although several cross-sectional and case-control studies have identified wrist posture as a risk factor for CTS, ${ }^{5} 6$ 27-30 National Institute for Occupational Safety and Health (NIOSH) found insufficient evidence that posture increased risk for CTS in a comprehensive review. ${ }^{31}$ In our study, posture, measured as the per cent time with $>30^{\circ}$ of wrist flexion or extension, was not associated with incident CTS. It is possible that the lack of association was due to the particular category cut-points used. Many studies have reported an increase in carpal pressure with increasing wrist extension or flexion ${ }^{32}$ and one study suggested that wrist extension greater than $33^{\circ}$ or wrist flexion greater than $49^{\circ}$ would increase CTS risk. ${ }^{33}$ Other literature suggests that $15^{\circ}$ of extension is the functional neutral wrist posture ${ }^{34}$; therefore, using a threshold of $45^{\circ}\left(15^{\circ}+30^{\circ}\right)$ of extension may be a better cut-point for risk assessment. However, the tasks performed by the workers in our cohort did not require much wrist extension or flexion. The cohort median per cent time in wrist flexion and wrist extension greater than $30^{\circ}$ were $5.6 \%$ and $0.6 \%$, respectively. Therefore, the postures observed among these study participants may have been of insufficient duration to increase risk. Another approach would have been to measure the per cent time in non-neutral wrist postures during forceful hand exertions. Fung $e t a l^{5}$ found increased risk of CTS among those with wrist flexion or extension that was forceful. Unfortunately, this type of analysis was not possible with our data set.

The interaction between force and repetition makes the relative distributions of their exposure levels important when estimating their individual associations with incident CTS. For example, in the stratified analysis (table 4A) workers exposed to a lower repetition rates $(<18$ repetitions/min) were not at elevated risk of CTS until exposed to high levels of peak hand forces (>4). However, for those performing jobs with higher hand repetition rates ( $>18$ repetitions/min), CTS risk increased nearly threefold with only moderate peak hand force $(>2.5$ and $\leq 4)$. This suggests that, at lower repetition rates workers may tolerate greater levels of force than they tolerate at higher repetition rates.

Although the presence of vibration exposure was not associated with CTS incidence in this cohort, the vibration metrics used were prone to substantial non-differential misclassification and may have biased findings towards the null. Studies with more precise measures of vibration have found associations between vibration and CTS. ${ }^{6} 3536$ The relationship between hand vibration exposure and risk of CTS should be explored with more complete and accurate exposure assessments.

Healthy worker survivor bias can attenuate exposure-response results due to the inclusion of participants hired well before study enrolment and the exclusion of prevalent cases diagnosed at baseline. ${ }^{37}$ To some extent, this bias may explain the increased rate of CTS that was observed among recent hires; for example, those hired within 3 years of enrolment. In this recent 
hire group, the rate of CTS among those exposed to high peak hand forces was approximately $50 \%$ greater than those with the same physical exposure, but hired more than three years prior to enrolment. A similar, albeit weaker, pattern was observed for those exposed to high forceful hand repetition rates. Yet the pattern for exposure to high per cent time in forceful hand exertions was no different between the two hire-date subgroups. It may be that the recently hired workers who are most susceptible to CTS leave high exertion jobs in less than 3 years. When estimating the same associations using cut-points of 5 or 7 years, there were no differences between subgroups, regardless of exposure metric or magnitude (data not shown in table 4). These findings suggest that the dropout associated with the healthy worker effect likely occurs in only the first few years of employment. The findings also suggest that effect estimates are likely underestimated in this analysis. Further research focused on new hires may clarify when and why workers choose to leave the workforce due to injury or difficulty tolerating certain physical exposures.

Our case definition for possible polyneuropathy, concurrent abnormal ulnar and median latency and CTS symptoms, was used to exclude incident CTS cases who might have polyneuropathy. The analysis was repeated after excluding all participants with concurrent abnormal median and ulnar nerve latencies regardless of symptoms; effect estimates were slightly increased for the exposure variables that included some measure of forceful hand exertion. There were no other important differences due to this change in definition of possible polyneuropathy.

\section{Limitations}

Several limitations should be considered based on differences in study designs between the five studies pooled for these analyses. ${ }^{11} 17$ Exposure data were not collected with identical methods across studies, likely increasing the possibility of nondifferential exposure misclassification and underestimation of effect estimates. ${ }^{11}$ The findings for vibration should be interpreted with caution because the assessments were simply dichotomised and the sample set was smaller than for the other analyses. The differences between study groups in the frequency of outcome assessments likely affected the temporal precision of diagnosis leading to some non-differential misclassification. In addition, it would have been useful to adjust for psychosocial factors in the analyses; the independent role of psychosocial factors in this cohort was investigated in a prior publication. ${ }^{18}$ However, the psychosocial variables were not available from one study group and an analysis was only possible with a substantially smaller sample size. Finally, the work history used in the assessment of healthy worker survivor bias only included the total years worked at the current employer and not prior employment.

\section{CONCLUSION}

In this prospective multicentre study of production and service workers, several measures of forceful occupational hand exertion were significantly associated with incident CTS after controlling for important covariates. Peak hand force, forceful hand repetition rate, and the per cent time in forceful hand exertion were each associated with the incident CTS in a dose-dependent pattern. Repetition rate for all hand exertions and the per cent time in any hand exertion (regardless of hand force) were not associated with an increased rate of CTS in this cohort. These findings support the conclusion that hand force is an important risk factor for CTS and do not support the conclusion that hand repetition, as distributed among the members of this study sample, is a risk factor for CTS. Workplace safety programmes may incorporate these findings into their strategies to prevent work-related CTS in production and service work.

\section{Author affiliations}

${ }^{1}$ Department of Environmental Health Sciences, University of California Berkeley, Berkeley, California, USA

${ }^{2}$ Department of Physical Therapy, Samuel Merritt University, Oakland, California, USA

${ }^{3}$ Center for Ergonomics, University of Wisconsin-Milwaukee, Milwaukee, Wisconsin, USA

${ }^{4}$ Rocky Mountain Center for Occupational and Environmental Health (RMCOEH), University of Utah, Salt Lake City, Utah, USA

${ }^{5}$ Division of General Medical Science, Washington University School of Medicine, Saint Louis, Missouri, USA

${ }^{6}$ Previously with the National Institute for Occupational Safety and Health (NIOSH), Cincinnati, Ohio, USA

${ }^{7}$ Safety and Health Assessment and Research for Prevention (SHARP) Program, Washington State Department of Labor and Industries, Olympia, Washington, USA

${ }^{8}$ Department of Occupational and Environmental Health, University of lowa, College of Public Health, lowa City, lowa, USA

${ }^{9}$ Division of Occupational and Environmental Medicine, University of California at San Francisco, San Francisco, California, USA

${ }^{10}$ Department of Bioengineering, University of California Berkeley, Berkeley, California, USA

Acknowledgements The authors would like to acknowledge the efforts of the research assistants from each of the research study groups who made the collection of the data possible and the study participants and employers for their time and willingness to participate in this study.

Funding This study was supported by research funding from the Center for Disease Control/National Institute for Occupational Safety and Health (RO1OH009712), and by Washington University Institute of Clinical and Translational Sciences Award (CTSA; grant \# UL1 TR000448) from the National Center for Advancing Translational Sciences (NCATS) of the National Institutes of Health (NIH)

\section{Competing interests None.}

Ethics approval University of California at San Francisco and Berkeley. Provenance and peer review Not commissioned; externally peer reviewed.

Open Access This is an Open Access article distributed in accordance with the Creative Commons Attribution Non Commercial (CC BY-NC 4.0) license, which permits others to distribute, remix, adapt, build upon this work non-commercially, and license their derivative works on different terms, provided the original work is properly cited and the use is non-commercial. See: http://creativecommons.org/ licenses/by-nc/4.0/

\section{REFERENCES}

1 Foley M, Silverstein B, Polissar N. The economic burden of carpal tunnel syndrome: long-term earnings of CTS claimants in Washington State. Am J Ind Med 2007:50:155-72.

2 Mondelli M, Giannini F, Giacchi M. Carpal tunnel syndrome incidence in a general population. Neurology 2002;58:289-94.

3 Violante FS, Armstrong TJ, Fiorentini C, et al. Carpal tunnel syndrome and manual work: a longitudinal study. J Occup Environ Med 2007;49:1189-96.

4 Silverstein BA, Fine LJ, Armstrong TJ. Occupational factors and carpal tunnel syndrome. Am J Ind Med 1987;11:343-58.

5 Fung BK, Chan KY, Lam LY, et al. Study of wrist posture, loading and repetitive motion as risk factors for developing carpal tunnel syndrome. Hand Surg 2007;12:13-18.

6 Maghsoudipour M, Moghimi S, Dehghaan F, et al. Association of occupational and non-occupational risk factors with the prevalence of work related carpal tunnel syndrome. J Occup Rehabil 2008;18:152-6.

7 Garg A, Kapellusch JM. Job analysis techniques for distal upper extremity disorders. Rev Hum Factors Ergon 2011;7:149-96.

8 Barbe MF, Gallagher S, Massicotte VS, et al. The interaction of force and repetition on musculoskeletal and neural tissue responses and sensorimotor behavior in a rat model of work-related musculoskeletal disorders. BMC Musculoskelet Disord 2013;14:303.

9 Gallagher S, Heberger JR. Examining the interaction of force and repetition on musculoskeletal disorder risk: a systematic literature review. Hum Factors 2013;55:108-24.

10 Roquelaure $Y$, Mechali S, Dano C, et al. Occupational and personal risk factors for carpal tunnel syndrome in industrial workers. $d J$ Work Environ Health 1997;23:364-9. 
11 Kapellusch J, Garg A, Bao S, et al. Pooling job physical exposure data from multiple sites in a study of carpal tunnel syndrome. Ergonomics 2013;56:1021-37.

12 American Conference of Governmental Industrial Hygienists (ACGIH). Threshold limit values for chemical substances and physical agents \& biological exposure indices. Cincinnati (OH): Signature Publications 2004:182-184. 2002.

13 Bonfiglioli R, Mattioli S, Armstrong T, et al. Validation of the ACGIH TLV for hand activity in the OCTOPUS cohort: a two-year longitudinal study of carpal tunnel syndrome. Scand J Work Environ Health 2013;39:155-63.

14 Gell N, Werner RA, Franzblau A, et al. A longitudinal study of industrial and clerical workers: incidence of carpal tunnel syndrome and assessment of risk factors. J Occup Rehabil 2005;15:47-55.

15 Garg A, Kapellusch J, Hegmann K, et al. The strain index (SI) and the threshold limit value (TLV) for hand activity level (HAL): risk of carpal tunnel syndrome (CTS) in a prospective cohort. Ergonomics 2012;55:396-414.

16 Punnett L, Wegman DH. Work-related musculoskeletal disorders: the epidemiologic evidence and the debate. J Electromyogr Kinesiology 2004;14:13-23.

17 Dale AM, Harris-Adamson C, Rempel D, et al. Prevalence and incidence of CTS in US working populations: pooled analysis of six prospective studies. Scand J Work Environ Health 2013;39:495-505.

18 Harris-Adamson C, Eisen EA, Dale AM, et al. Personal and workplace psychosocial risk factors for carpal tunnel syndrome: a pooled study cohort. Occup Environ Med 2013;70:529-37.

19 Borg G. Psychophysical bases of perceived exertion. Med Sci Sports Exerc 1982;14:377-81.

20 Rempel D, Evanoff B, Amadio P, et al. Consensus criteria for the classification of carpal tunnel syndrome in epidemiologic studies. Am J Public Health 1998;88:1447-51.

21 Rothman KJ, Greenland S, Lash TL. Modern epidemiology. 3rd edn. Philadelphia, PA: Lippincott, Williams \& Wilkins, 2008:130-4.

22 Eisen EA, Agalliu I, Coull B, et al. Smoothing methods applied to occupational cohort studies; illustrated by penalized splines. Occup Environ Med 2004;61:854-60.

23 Gorsche RG, Wiley JP, Renger RF, et al. Prevalence and incidence of carpal tunnel syndrome in a meat packing plant. Occup Environ Med 1999;56:417-22.

24 Nordander C, Ohlsson K, Akesson I, et al. Exposure-response relationships in work-related musculoskeletal disorders in elbows and hands - a synthesis of group-level data on exposure and response obtained using uniform methods of data collection. App/ Ergon 2013;44:241-53.
25 Latko WA, Armstrong TJ, Foulke JA, et al. Development and evaluation of an observational method for assessing repetition in hand tasks. Am Ind Hyg Assoc J 1997;58:278-85.

26 Stayner L, Steenland K, Dosemeci M, et al. Attenuation of exposure-response curves in occupational cohort studies at high exposure levels. Scand J Work Environ Health 2003;29:317-24.

27 Armstrong TJ, Chaffin DB. Carpal tunnel syndrome and selected personal attributes. J Occup Med 1979;21:481-6.

28 de Krom MC, Kester AD, Knipschild PG, et al. Risk factors for carpal tunnel syndrome. Am J Epidemiol 1990;132:1102-10.

29 English CJ, Maclaren WM, Court-Brown C, et al. Relations between upper limb soft tissue disorders and repetitive movements at work. Am J Ind Med 1995;27:75-90.

30 Tanaka S, Wild DK, Seligman PJ, et al. Prevalence and work-relatedness of self-reported carpal tunnel syndrome among U.S. workers: analysis of the Occupational Health Supplement data of 1988 National Health Interview Survey. Am J Ind Med 1995:27:451-70.

31 Bernard B. Musculoskeletal disorders and workplace factors: a critical review of epidemiologic evidence for work-related musculoskeletal disorders of the neck, upper extremity, and low back. Cincinnati, OH, US: Department of Health and Human Services, Public Health Service, Centers for Disease Control and Prevention, National Institute for Occupational Safety and Health; DHHS (NIOSH) Publication No. 97-141, 1997.

32 Rempel D, Lundborg G, Dahlin L. Pathophysiology of nerve compression syndrome: response of peripheral nerves to loading. J Bone Joint Surg 1999;81-A: 1600-10

33 Keir PJ, Bach JM, Hudes M, et al. Guidelines for wrist posture based on carpal tunnel pressure thresholds. Hum Factors 2007;49:88-9.

34 Lee KS, Jung MC. Flexion and extension angles of resting fingers and wrist. Int J Occup Saf Ergon 2014;20:91-101.

35 Armstrong T, Dale AM, Franzblau A, et al. Risk factors for carpal tunnel syndrome and median neuropathy in a working population. J Occup Environ Med 2008;50:1355-64.

36 Wieslander G, Norback D, Gothe CJ, et al. Carpal tunnel syndrome (CTS) and exposure to vibration, repetitive wrist movements, and heavy manual work: a case-referent study. Br J Ind Med Occup 1989;46:43-7.

37 Applebaum KM, Malloy EJ, Eisen EA. Left truncation, susceptibility, and bias in occupational cohort studies. Epidemiology 2011;22:1397-404. 